\title{
Hospitalization-based major comorbidity of inflammatory bowel disease in Canada
}

\author{
Charles $\mathrm{N}$ Bernstein $\mathrm{MD}^{1}$, Alice Nabalamba $\mathrm{PhD}^{2}$
}

\author{
CN Bernstein, A Nabalamba. Hospitalization-based major \\ comorbidity of inflammatory bowel disease in Canada. Can J \\ Gastroenterol 2007;21(8):507-511.
}

OBJECTIVE: To define the patterns of hospitalization for known major comorbidities associated with inflammatory bowel disease (IBD) in Canada.

METHODS: The data source was the Statistics Canada Health Person Oriented Information hospital database (1994/1995 to 2003/2004). The number of stays for a diagnosis of Crohn's disease or ulcerative colitis by the International Classification of Diseases, ninth edition, codes 555 or 556, or the International Classification of Diseases, 10 th edition, Canadian Enhancement, codes K50 or K51, was extracted. Age- and sex-specific and age-adjusted rates of hospitalization for selected IBD-related comorbidities were assessed.

RESULTS: Rates of Hodgkin's disease and non-Hodgkin's lymphoma were low in the hospitalized IBD population. Rates for colon cancer, rectal cancer, pulmonary emboli and deep venous thromboembolism were generally higher among IBD patients younger than 50 years of age compared with the non-IBD hospitalized population. CONCLUSIONS: IBD was associated with life-threatening comorbidities such as venous thromboembolic disease and colon cancer among persons younger than 50 years of age to a greater extent than the general hospitalized population. Recent secular trends in rates of non-Hodgkin's lymphomas will need to be followed to determine whether the whole population, including IBD patients who receive immunomodulating therapies, are at increased risk.

Key Words: Cancer; Crohn's disease; Hospitalization; Inflammatory bowel disease; Lymphoma; Ulcerative colitis; Venous thromboembolism

\author{
Principales affections concomitantes des mala- \\ dies intestinales inflammatoires, d'après les \\ hospitalisations, au Canada
}

BUT : L'étude avait pour but d'établir les tendances en matière d'hospitalisation pour les principales affections concomitantes connues des maladies intestinales inflammatoires (MII), au Canada.

MÉTHODE : La source de renseignements était la base de données personnalisées sur la santé de Statistique Canada (1994-1995 à 2003-2004). Nous avons extrait le nombre de séjours motivés par un diagnostic de maladie de Crohn ou de colite ulcéreuse selon la $9^{\text {e }}$ révision de la Classification internationale des maladies (CIM), c'est-à-dire les codes 555 ou 556, ou selon la version canadienne améliorée de la $10^{\mathrm{e}}$ révision de la CIM, c'est-à-dire les codes K50 ou K51. Il y a eu évaluation des taux d'hospitalisation selon l'âge et le sexe et des taux d'hospitalisation rajustés selon l'âge pour les affections concomitantes des MII retenues.

RÉSULTATS : Les taux de maladie de Hodgkin et de lymphome non hodgkinien étaient faibles chez les patients hospitalisés pour une MII. Les taux de cancer du côlon et de cancer du rectum, d'embolie pulmonaire et de thrombo-embolie veineuse profonde étaient généralement plus élevés chez les patients âgés de moins de 50 ans, atteints d'une MII que chez les malades hospitalisés pour d'autres affections qu'une MII.

CONCLUSIONS : Les MII étaient plus fortement associées à des maladies concomitantes potentiellement mortelles comme les thromboembolies veineuses et le cancer du côlon chez les patients de moins de 50 ans que chez les malades hospitalisés en général. Il faudra suivre les tendances séculaires récentes en ce qui concerne les taux de lymphome non hodgkinien pour savoir si la population de patients soumis à un traitement immunomodulateur, y compris les patients atteints d'une MII, sont exposés à un risque accru.

The present study used hospital morbidity data to determine the hospitalization burden of IBD in Canada between $1994 / 1995$ and 2003/2004. We extracted information on hospitalizations for selected comorbidities by identifying diseases by International Classification of Diseases, ninth edition (ICD-9) codes and by ICD, 10th edition, Canadian enhancement (ICD-10-CA) codes for data in the years $2001 / 2002$ to 2003/2004. Hence, the burden of these comorbidities on patients with IBD across Canada for the years under study and the patterns of the disease by age and sex could be determined.

\section{METHODS}

Data source

Hospitalization data for $1994 / 1995$ to $2003 / 2004$ were from Statistics Canada's Health Person Oriented Information (HPOI) database, which consists of information on inpatient cases separated as a discharge or death from acute care hospitals with IBD than in the general population.

${ }^{1}$ Department of Internal Medicine and University of Manitoba Inflammatory Bowel Disease Clinical and Research Centre, Winnipeg, Manitoba;

${ }^{2}$ Health Statistics Division, Statistics Canada, Ottawa, Ontario

Correspondence: Dr Charles N Bernstein, 804F-715 McDermot Avenue, University of Manitoba, Winnipeg, Manitoba R3E 3P4.

Telephone 204-789-3369, fax 204-789-3972, e-mail cbernst@cc.umanitoba.ca

Received for publication June 18, 2006. Accepted November 6, 2006 
during the year. The HPOI database is national in scope and derived from the Hospital Morbidity Database, a data holding of the Canadian Institute of Health Information (CIHI). Each record in the HPOI can contain demographic (eg, date of birth, sex and postal codes), administrative (eg, scrambled or unscrambled health insurance numbers, dates of admission, discharge or transfer) and clinical information (eg, diagnoses, operative and nonoperative interventions, and causes of injuries). Information on newborns, patients without proper health insurance numbers and those treated outside their home province are automatically excluded from the HPOI database.

The data are based on the April to March fiscal year. Canadian provinces and territories have switched from ICD-9 to ICD-10. CA over a number of years. In the fiscal years 1994/1995 to 2000/2001, all diagnoses were coded according to ICD-9 definitions. ICD-10-CA coding was used in 2001/2002 by six of 13 Canadian provinces and territories and by 2003/2004 it was used by 11 provinces; the remaining jurisdictions continued to use the ICD-9 coding algorithm.

\section{Analysis}

The frequency of known comorbidities in IBD was assessed, using patients' hospital discharge records. The following comorbidities were selected in accordance with the ICD-9, or ICD-10. $\mathrm{CA}$ as provided by the individual provinces: colon cancer (ICD-9: 153.x or ICD-10-CA: C18), rectal cancer (ICD-9: 154.x or ICD-10-CA: C19-C21), non-Hodgkin's lymphoma (ICD-9: 200.x or ICD-10-CA: C83.2, C83.3, C83.4, C83.5, C83.7, C96.3 and C88.08), Hodgkin's disease (ICD-9: 201.x or ICD-10-CA: C81), pulmonary emboli (ICD-9: 415.x or ICD10-CA: I26) and deep venous thromboembolism (ICD-9: 451.x-454.x or ICD-10-CA: I80-I82).

These conditions were chosen because they were likely to result in hospitalizations and were not likely to be associated with miscoding. As well, for provinces and territories that switched to coding with the ICD-10-CA algorithm, the conditions were assigned a grading of good or excellent match, indicating that the ICD-9 and ICD-10-CA coding systems were either identical or the ICD-10-CA terms were indexed to the ICD-9 codes (Appendix). In contrast, diagnoses of fractures would not be all-inclusive, because many fractures are treated in an outpatient setting and would be missed. The diagnosis of cholangitis was also excluded, because diagnoses of secondary cholangitis would confound the assessment for primary sclerosing cholangitis (a known comorbidity in IBD).

From the overall inpatient cases in acute care facilities of 2.5 to 3.2 million each year, between 22,000 and 25,000 cases were classified as having Crohn's disease (CD) (ICD-9: 555 or ICD-10-CA: K50) or ulcerative colitis (UC) (ICD-9: 556 or ICD-10-CA: K51). While CD or UC was one of 16 to 25 possible diagnosis codes on the discharge record, it was the diagnosis most responsible for the length of stay at the hospital $50 \%$ of the time.

Age-adjusted rates of the selected comorbidities in IBD and non-IBD hospitalizations were calculated using the direct standardization method. The proportions of cases admitted with the comorbidity were standardized to fiscal year 1994/1995. When doing a trend analysis that straddles the two coding systems, however, there is a potential for confounding in trend patterns resulting from coding anomalies across provinces. For example, when some provinces switched from ICD-9 to ICD-10-CA, there was a tendency to report fewer comorbidities (12). Although this could be a reflection of the fact that more severe comorbidities are being weighted more heavily and more likely to be coded, it was decided to report average rates of the selected comorbidities in IBD and non-IBD populations, rather than annual rates. RR ratios and $95 \%$ CIs were calculated to compare the rates of the selected comorbidities in IBD and non-IBD general hospitalized populations, after adjustment for potential confounding by age and sex of patients.

\section{RESULTS}

The rates of colon cancer, rectal cancer, Hodgkin's disease, nonHodgkin's lymphoma, pulmonary emboli and deep venous thromboembolism cases identified in IBD and non-IBD hospitalized populations over the 10-year period of the study are displayed in Figure 1. Overall, colon and rectal cancers were present in $0.5 \%$ and $0.3 \%$ of the IBD hospitalizations, respectively. Hodgkin's disease and non-Hodgkin's lymphoma were found in $0.02 \%$ and $0.03 \%$, respectively of the IBD cases, while pulmonary emboli and deep venous thromboembolism were found in $0.5 \%$ and $1.18 \%$, respectively, of the IBD cases. The proportions of these comorbidities in the non-IBD hospitalized population were slightly higher, with the exception of pulmonary emboli and deep venous thromboembolism.

After adjusting for age, the rates of colon cancer and rectal cancer in IBD were higher than those in the non-IBD population younger than 50 years of age (Table 1 ). On the other hand, the rates for pulmonary emboli and deep venous thromboembolism were higher in IBD than in non-IBD hospitalizations regardless of age, while Hodgkin's disease and non-Hodgkin's lymphoma appeared to be unrelated to age in both IBD and non-IBD hospitalizations.

Generally, the overall rate of both colon and rectal cancers in IBD was higher among males than females, which reflected a male predilection in the general population as well (13) (Table 2). Similarly, rates of pulmonary emboli and deep venous thromboembolism were higher in males than females. There was no statistical difference between males and females with respect to Hodgkin's disease and non-Hodgkin's lymphoma in IBD.

\section{DISCUSSION}

During the 10-year period of our study, the age-adjusted rate of hospitalization for CD declined (2). The age-adjusted rate for $\mathrm{UC}$ was stable. Overall, hospitalization rates for UC were $40 \%$ to $50 \%$ of those for CD (2). Hospitalized CD patients were more likely to be female and there was no sex differential in UC (2). The peak age of hospitalization that occurred in the third decade mirrored the results of peak age of incidence of CD from elsewhere (14-16).

Although there were some statistically significant disparities compared with the national average, overall, the ratio of CD to UC admissions, the rates of major surgery of all admissions and the readmission rates were mostly homogeneous across the country (2). Recently, epidemiological data from five Canadian provinces, using the administrative definition of IBD validated previously, showed similar rates in Manitoba, Alberta and Saskatchewan for both CD and UC, with lower rates in British Columbia balancing out higher rates in Nova Scotia (13). These data mirrored hospitalization trends for IBD among the provinces (1). The relative uniformity across the country in these two reports suggests that the numbers of IBD patients across Canada and the likelihood that they will need hospitalization is consistent. 


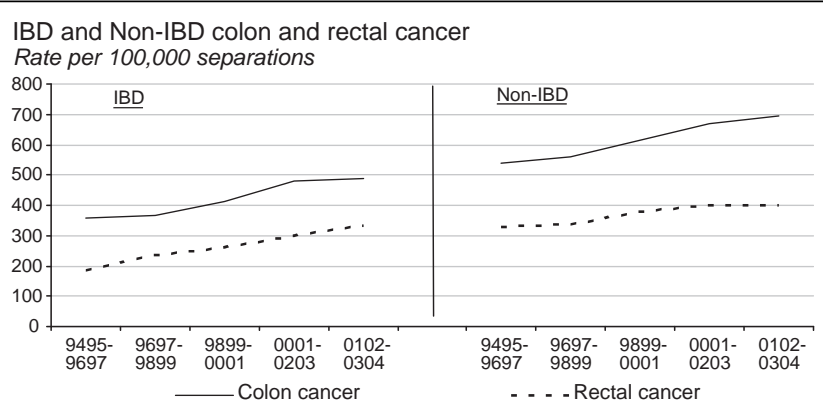

IBD and Non-IBD Hodgkin's disease and Non-Hodgkin's lymphoma Rate per 100,000 separations

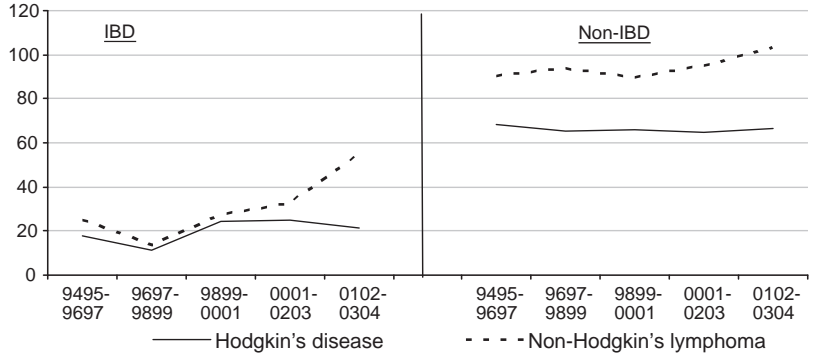

IBD and Non-IBD pulmonary emboli and deep venous thromboembolism Rate per 100,000 separations

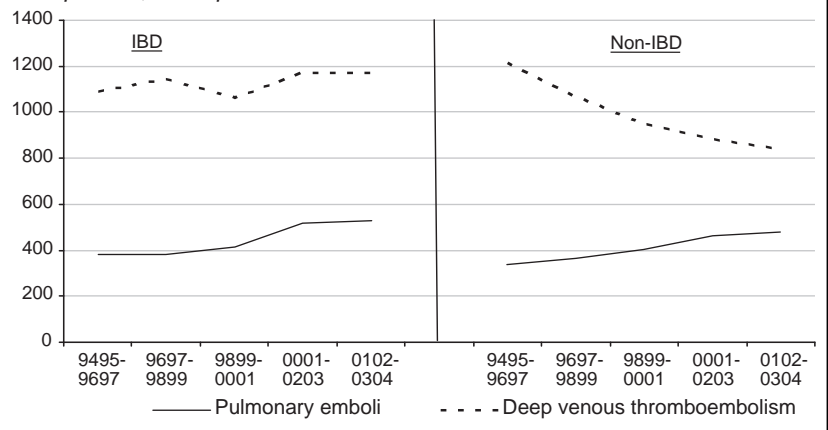

Figure 1) Age-adjusted rates for select comorbidities in inflammatory bowel disease (IBD) and non-IBD hospital separations, 1994/1995 to 2003/2004, Canada. Rates are based on three-year moving averages of frequencies. Data from Statistics Canada Hospital Morbidity Database, 1994/1995 to 2003/2004

There was a rise in cases of colon cancer and rectal cancer among IBD and non-IBD patients. However, for those younger than 50 years of age, the RR was twofold among IBD versus non-IBD patients. This most likely reflects the known increased risk of colon cancer in IBD and rectal cancer in UC (16), and colorectal cancer admissions would be uncommon among those younger than 50 years of age without a predisposing condition, such as IBD. The rates among IBD patients for those 50 years of age and older were, if anything, less than nonIBD patients.

The estimated prevalence of IBD in Canada during the later years of the study was approximately 150,000, and on that basis the rate of colon cancer diagnosis was approximately $0.1 \%$. Previous estimates have ranged from $0.25 \%$ to $0.33 \%(9,17)$ so the data in the present paper are in line with these previous figures. Furthermore, the entire population of IBD is likely not at risk for colon cancer. Patients with CD who have minimal or no colonic involvement are not at increased risk. The more shallow rise of rectal cancers over time may reflect that CD, which makes up more than $50 \%$ of the national population of
TABLE 1

Age-specific comorbidity rates* in inflammatory bowel disease (IBD) versus non-IBD hospitalizations, 1994/1995 to $2003 / 2004$, Canada

\begin{tabular}{|c|c|c|c|c|}
\hline \multirow[b]{2}{*}{ Comorbidity } & \multicolumn{2}{|c|}{ Rate per 100,000} & \multicolumn{2}{|c|}{$\begin{array}{c}\mathrm{RR} \text { of } \\
\text { comorbidity in IBD } \\
\text { vesus non-IBD }\end{array}$} \\
\hline & IBD & Non-IBD & $\mathbf{R R}$ & $95 \% \mathrm{Cl}$ \\
\hline \multicolumn{5}{|l|}{ Younger than $\mathbf{5 0}$ years } \\
\hline Colon cancer & 188.14 & 90.36 & 2.08 & $1.62-2.68$ \\
\hline Rectal cancer & 152.51 & 69.62 & 2.19 & $1.65-2.91$ \\
\hline Hodgkin's disease & 17.82 & 86.74 & 0.21 & $0.12-0.34$ \\
\hline Non-Hodgkin's lymphoma & 19.95 & 67.92 & 0.29 & $0.18-0.48$ \\
\hline Pulmonary emboli & 302.16 & 180.60 & 1.67 & $1.39-2.01$ \\
\hline Deep venous thromboembolism & 765.39 & 499.46 & 1.53 & $1.37-1.71$ \\
\hline \multicolumn{5}{|l|}{50 years and older } \\
\hline Colon cancer & 1055.17 & 1178.61 & 0.90 & $0.82-0.97$ \\
\hline Rectal cancer & 573.16 & 690.71 & 0.83 & $0.74-0.93$ \\
\hline Hodgkin's disease & 27.81 & 44.94 & 0.62 & $0.39-0.99$ \\
\hline Non-Hodgkin's lymphoma & 61.80 & 122.28 & 0.51 & $0.37-0.69$ \\
\hline Pulmonary emboli & 807.98 & 642.55 & 1.26 & $1.13-1.39$ \\
\hline Deep venous thromboembolism & 2087.16 & 1579.44 & 1.32 & $1.24-1.41$ \\
\hline
\end{tabular}

${ }^{*}$ Rates are based on 10-year combined frequencies. Data from Statistics Canada Health Person Oriented Information Database, 1994/95 to 2003/04

TABLE 2

Sex-specific comorbidity rates* in inflammatory bowel disease hospitalizations, $1994 / 1995$ to $2003 / 2004$, Canada

\begin{tabular}{|c|c|c|c|c|}
\hline \multirow[b]{2}{*}{ Comorbidity } & \multicolumn{2}{|c|}{ Rate per 100,000} & \multicolumn{2}{|c|}{$\begin{array}{c}\text { RR of } \\
\text { comorbidity } \\
\text { males versus } \\
\text { females }\end{array}$} \\
\hline & Male & Female & $\mathbf{R R}$ & $95 \% \mathrm{Cl}$ \\
\hline Colon cancer & 581 & 300 & 1.93 & $1.68-2.22$ \\
\hline Rectal cancer & 374 & 171 & 2.19 & $1.82-2.62$ \\
\hline Hodgkin's disease & 26 & 18 & 1.45 & $0.79-2.66$ \\
\hline Non-Hodgkin's lymphoma & 40 & 27 & 1.49 & $0.91-2.43$ \\
\hline Pulmonary emboli & 482 & 401 & 1.20 & $1.05-1.37$ \\
\hline Deep venous thromboembolism & 1207 & 1043 & 1.16 & $1.07-1.26$ \\
\hline
\end{tabular}

${ }^{*}$ Rates are based on 10-year combined frequencies. Data from Statistics Canada Health Person Oriented Information Database, 1994/1995 to 2003/2004

IBD patients, is not associated with an increased risk for rectal cancer (9).

Patients with IBD had relatively lower rates of both nonHodgkin's lymphoma and Hodgkin's disease compared with non-IBD patients. These data support the notion that immunomodulatory drugs are not having a significant impact on increasing risk for lymphomas in IBD. Assuming that most patients with lymphoma get admitted to hospital even for one overnight stay over the course of their illness, the incidence of lymphoma was generally low and the rates over time were stable. There was an increase in the overall rate of non-Hodgkin's lymphoma in both IBD and non-IBD patients after 2001/2002, which may be the result of more provincial jurisdictions switching to ICD-10-CA coding because there was no change in number of cases in those 
provinces that continued to report in ICD-9 or ICD-9-Clinical Modification. It is also not likely to be simply related to increased capture of hospital data because numbers of admissions for venous thromboembolism among non-IBD subjects steadily fell over time.

Older persons were more likely to have non-Hodgkin's lymphoma. It has previously been reported that males with $\mathrm{CD}$ were significantly more likely to get non-Hodgkin's lymphoma than the general population (9) and these males on average were older at the age of presentation of CD than the general $\mathrm{CD}$ population. Hodgkin's disease was uncommon in IBD, as opposed to what was reported in other studies (11).

There was a trend toward increasing venous thromboembolism over time, including among young people. Overall, the prevalence of venous thromboembolism declined in non-IBD patients and plateaued in IBD patients. It is likely that most venous thromboembolic events were captured using hospital-based data because outpatient management of these events with subcutaneous heparins was much less common in the 1990s than in current practice. The increased RR of venous thromboembolism has been reported previously (10). Overall, the rates of pulmonary emboli and venous thromboembolism were greater among IBD cases than the non-IBD population, but particularly among those younger than 50 years of age. While it is possible that physicians may be more likely to seek venous thrombosis diagnoses in IBD patients than in non-IBD patients, the increased RR of venous thrombosis in IBD versus non-IBD patients has been reported in a population-based sample. Furthermore, rates of venous thromboembolism appear to be rising in IBD but falling in non-IBD patients. This may reflect the increasing trend toward treating venous thromboembolism in the outpatient setting, whereas IBD patients may be acquiring their deep venous thromboembolism while already admitted to hospital (ie, during active inflammatory disease or postsurgically). These data add further support to encouraging clinicians to be more vigilant in providing prophylaxis against venous thrombosis in younger IBD patients when they are admitted.
Our study does have some significant limitations that require further explanation. First, our analysis was performed using administrative health care data collected from hospitals across Canada. Thus, the accuracy of our findings is in part dependent on the precision of diagnosis coding by the hospitals' medical records personnel. Second, the HPOI database primarily concerns patients treated in acute care hospitals. Patients treated at a hospital but not admitted for an overnight stay were excluded, as well as those treated on an outpatient basis. Furthermore, the data in the present paper only capture patients diagnosed with these comorbidities who were hospitalized. It is reasonable to consider for all of the conditions in question that at least one hospitalization would have taken place. Certainly for colon and rectal cancer, at least one surgery admission would be expected. While the rates for colon and rectal cancer, pulmonary emboli and venous thromboembolism in IBD appeared to be rising, it was not possible to conclusively describe these changes because they may have been confounded by a number of factors, including reporting anomalies across provinces (12). It is plausible that we have underestimated the numbers of lymphoma and Hodgkin's disease diagnoses in any one year.

\section{CONCLUSION}

The data presented in the present paper can be helpful to analyze changes in these major comorbidities over time. If it is found that colon cancer rates fall over time, this may give insight into possible mechanisms based on secular trends in practice. If lymphoma rates rise, this would mandate exploration of therapeutic choices in patients. If lymphoma rates do not rise, this would lend confidence to the current practice of pursuing immunosuppression fairly aggressively and using some of the newer biological agents that have raised fears of lymphoma risk. In fact, the finding of relatively lower rates of lymphoma in IBD compared with the non-IBD population should provide an important baseline upon which to analyze these data, because the use of biologicals have steadily increased since 2001. Therefore, a reassessment of these data by collecting the next nine years of data (in 2011) should be very instructive.

\section{APPENDIX}

The International Classification of Diseases, ninth edition (ICD-9) and the ICD, 10th edition, Canadian enhancement (ICD-10-CA) comorbidity codes

\begin{tabular}{|c|c|c|c|c|}
\hline Condition & Code & ICD-9 Definition & Code & ICD-10-CA Definition \\
\hline Colon cancer & $153 . x$ & Malignant neoplasm of colon & C18 & Malignant neoplasm of colon \\
\hline \multirow[t]{3}{*}{ Rectal cancer } & 154.x & Malignant neoplasm of rectum, rectosigmoid junction & C19 & Malignant neoplasm of rectosigmoid junction \\
\hline & & and anus & $\mathrm{C} 20$ & Malignant neoplasm of rectum \\
\hline & & & $\mathrm{C} 21$ & Malignant neoplasm of anus and anal canal \\
\hline \multirow[t]{7}{*}{ Non-Hodgkin's lymphoma } & 200.8 & Other named variants & C83.2 & $\begin{array}{l}\text { Mixed small and large cell (diffuse) Non-Hodgkin's } \\
\text { lymphoma }\end{array}$ \\
\hline & 200 & Reticulosarcoma & C83.3 & $\begin{array}{l}\text { Large cell (diffuse) Non-Hodgkin's lymphoma } \\
\text { (includes recticulum cell sarcoma) }\end{array}$ \\
\hline & 200.8 & Other named variants & C83.4 & Immunoblastic (diffuse) Non-Hodgkin's lymphoma \\
\hline & 200.1 & Lymphosarcoma (excludes lymphosarcoma cell leukemia) & C83.5 & Lymphoblastic (diffuse) Non-Hodgkin's lymphoma \\
\hline & 200.2 & Burkitt's tumour & C83.7 & Burkitt's tumour \\
\hline & 200.8 & Other named variants & C88.08 & Other lymphoplasmacytic lymphoma \\
\hline & 200 & Reticulosarcoma & C96.3 & True histiocytic lymphoma \\
\hline Hodgkin's disease & 201.x & Hodgkin's disease & C81 & Hodgkin's disease \\
\hline Pulmonary embolism & 415.x & Acute pulmonary heart disease & 126 & Pulmonary embolism \\
\hline
\end{tabular}


APPENDIX - CONTINUED

The International Classification of Diseases, ninth edition (ICD-9) and the ICD, 10th edition, Canadian enhancement (ICD-10-CA) comorbidity codes

\begin{tabular}{|c|c|c|c|c|}
\hline Condition & Code & ICD-9 Definition & Code & ICD-10-CA Definition \\
\hline Deep venous & 451 & Phlebitis and thrombophlebitis & 180 & Phlebitis and thrombophlebitis \\
\hline \multirow[t]{3}{*}{ thromboembolism } & 452 & $\begin{array}{l}\text { Portal vein thrombosis (Includes portal [vein] obstruction. } \\
\text { Excludes phlebitis of portal vein) }\end{array}$ & 181 & $\begin{array}{l}\text { Portal vein thrombosis (Includes portal [vein] } \\
\text { obstruction. Excludes phlebitis of portal vein) }\end{array}$ \\
\hline & 453 & Other venous embolism and thrombosis & 182 & Other venous embolism and thrombosis \\
\hline & 454 & Varicose veins of lower extremities & 183 & Varicose veins of lower extremities \\
\hline
\end{tabular}

\section{REFERENCES}

1. Nabalamba A, Bernstein CN, Seko C. Inflammatory bowel disease: Hospitalization. Health Rep 2004;15:25-40.

2. Bernstein $\mathrm{CN}$, Nabalamba A. Hospitalization, surgery, and readmission rates of IBD in Canada: A population-based study. Am J Gastroenterol 2006;101:110-8.

3. Longobardi T, Jacobs P, Bernstein CN. Utilization of health care resources by individuals with inflammatory bowel disease in the United States: A profile of time since diagnosis. Am J Gastroenterol 2004;99:650-5.

4. Longobardi T, Wajda A, Blanchard JF, Bernstein CN. Patterns of utilization of health care resources in Manitoba by patients with IBD. Gastroenterology 2005;128:A322 (American Gastroenterology Association, Chicago, IL, 05/05)

5. Farrokhyar F, Swarbrick ET, Grace RH, Hellier MD, Gent AE, Irvine EJ. Low mortality in ulcerative colitis and Crohn's disease in three regional centers in England. Am J Gastroenterol 2001;96:501-7.

6. Jess T, Winther KV, Munkholm P, Langholz E, Binder V. Mortality and causes of death in Crohn's disease: Follow-up of a populationbased cohort in Copenhagen County, Denmark. Gastroenterology 2002;122:1808-14.

7. Masala G, Bagnoli S, Ceroti M, et al. Divergent patterns of total and cancer mortality in ulcerative colitis and Crohn's disease patients: The Florence IBD study 1978-2001. Gut 2004;53:1309-13. (Erratum in 2004;53:1722).

8. Ekbom A, Helmick C, Zack M, Adami HO. Ulcerative colitis and colorectal cancer. A population-based study. N Engl J Med 1990;323:1228-33.
9. Bernstein CN, Blanchard JF, Kliewer E, Wajda A. Cancer risk in patients with inflammatory bowel disease: A population-based study. Cancer 2001;91:854-62.

10. Bernstein CN, Blanchard JF, Houston D, Wajda A. The incidence of deep venous thrombosis and pulmonary embolism among patients with inflammatory bowel disease: A population-based cohort study. Thromb Haemost 2001;85:430-4.

11. Palli D, Trallori G, Bagnoli S, et al. Hodgkin's disease risk is increased in patients with ulcerative colitis. Gastroenterology 2000;119:647-53.

12. Quan H, Sundararajan V, Halfon P, et al. Coding algorithms for defining comorbidities in ICD-9-CM and ICD-10 administrative data. Med Care 2005;43:1130-9.

13. Bernstein CN, Wajda A, Blanchard JF, et al. The burden of IBD in Canada: A population-based study. Gastroenterology 2005;128:A114 (American Gastroenterology Association, Chicago, IL, 05/05).

14. Bernstein CN, Blanchard JF, Rawsthorne P, Wajda A. The epidemiology of Crohn's disease and ulcerative colitis in a central Canadian province: A population-based study. Am J Epidemiol 1999;149:916-24.

15. Loftus EV, Schoenfeld P, Sandborn WJ. The epidemiology and natural history of Crohn's disease in population-based cohorts from North America: A systematic review. Aliment Pharmacol Ther 2002;16:51-60.

16. Russel MG, Stockbrugger RW. Epidemiology of inflammatory bowel disease: An update. Scand J Gastroenterol 1996;31:417-27.

17. Eaden JA, Abrams KR, Mayberry JF. The risk of colorectal cancer in ulcerative colitis: A meta-analysis. Gut 2001;48:526-35. 


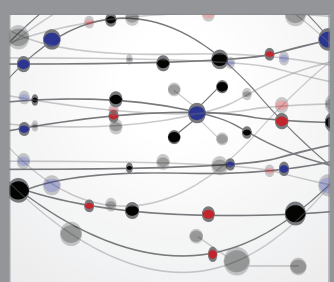

The Scientific World Journal
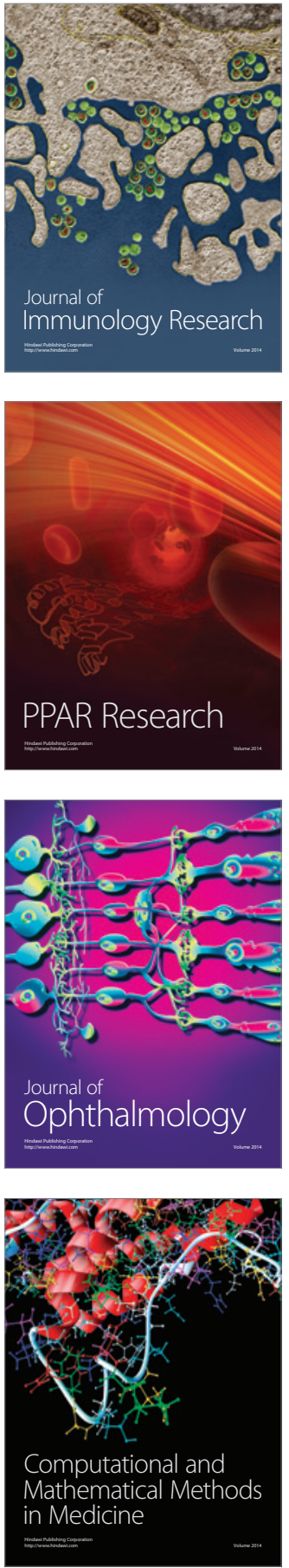

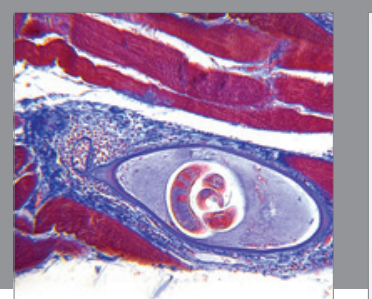

Gastroenterology Research and Practice

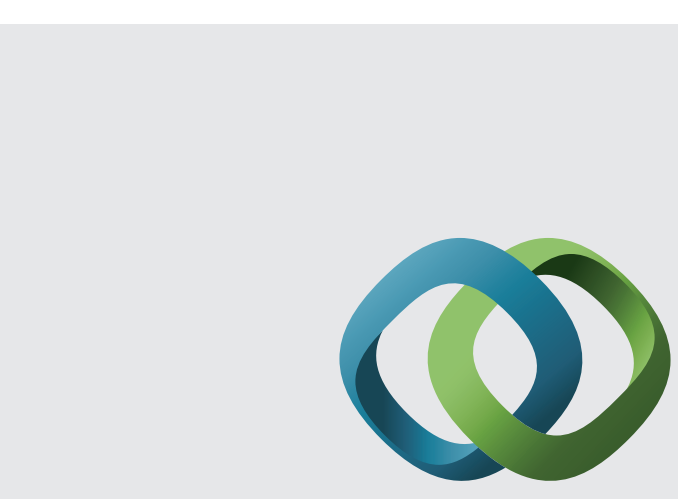

\section{Hindawi}

Submit your manuscripts at

http://www.hindawi.com
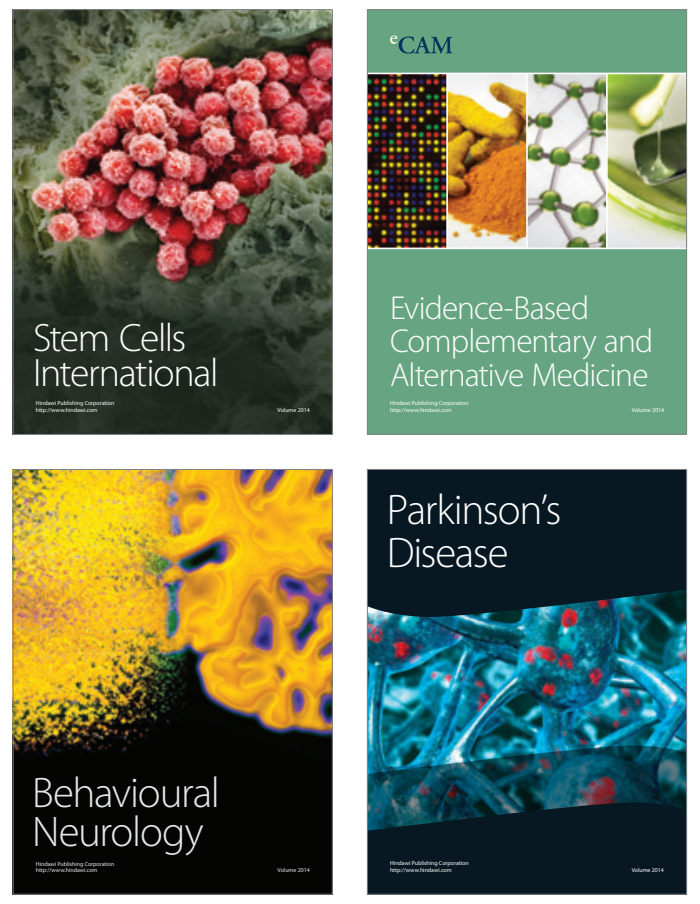
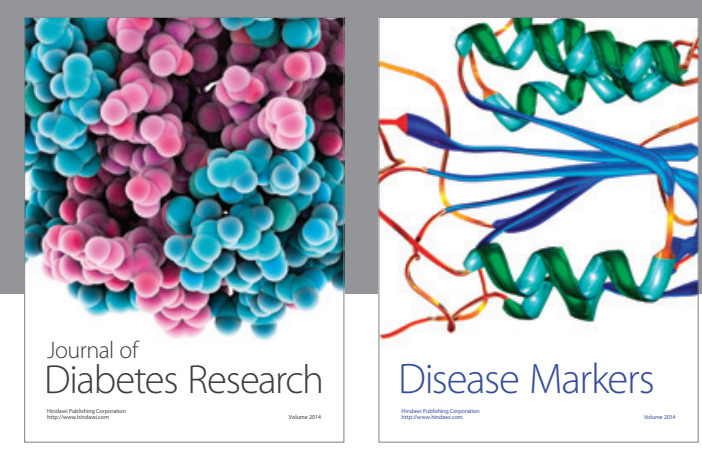

Disease Markers
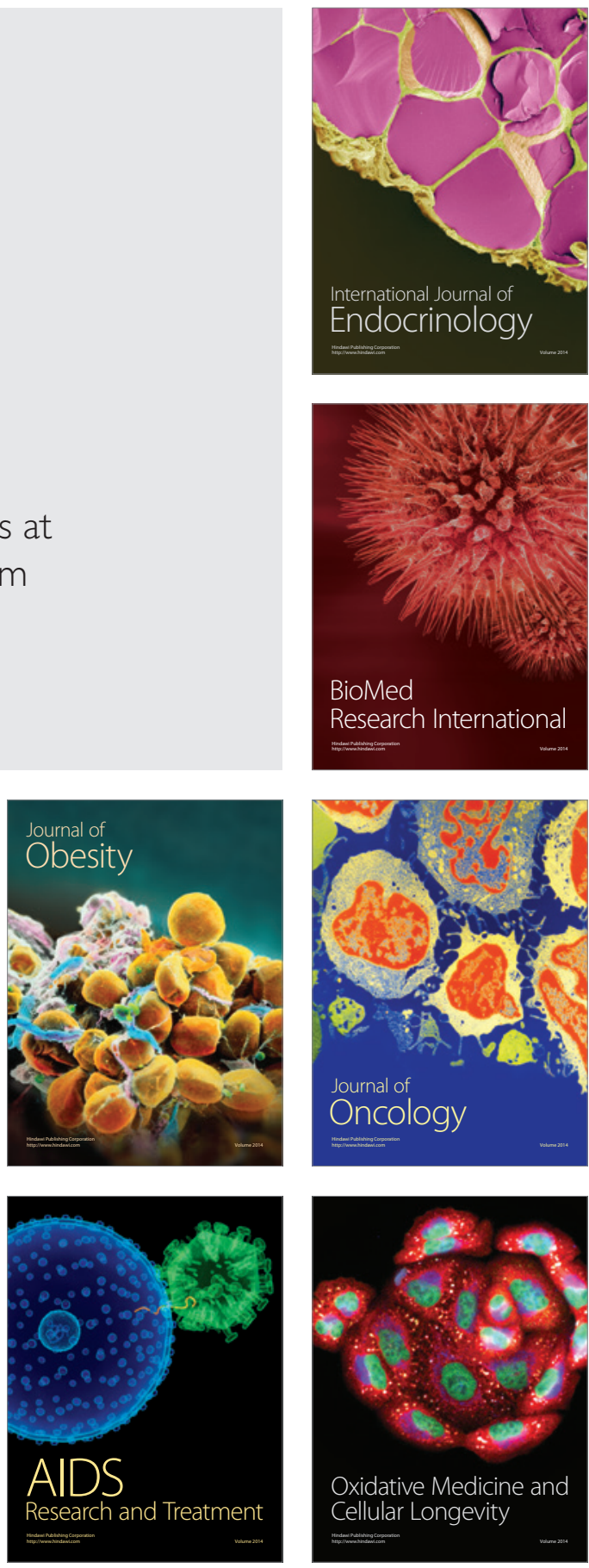